\title{
CASO imatinib: ANÁlisis TÉCNICO Y JURÍDICO DEL TRÁMITE DE PATENTE EN COLOMBIA
}

\author{
LUISA FERNANDA DÍAZ-PINILLA* \\ RAFAEL GUEVARA** \\ NATALIA LAMPREA*** \\ ÓSCAR LIZARAZO-CORTÉS ${ }^{* * * *}$
}

\section{INTRODUCCIÓN}

Imatinib -comercialmente disponible en forma de mesilato de Imatinib como Gleevec $^{\circledR}$ o Glivec ${ }^{\circledR}$ - es un representante de la denominada "terapia dirigida", que cuenta con actividad altamente selectiva en el tratamiento de leucemia mieloide crónica (CML, por sus siglas en inglés) y tumores del estroma gastrointestinal (GIST, por sus siglas en inglés), entre otros, al ser un inhibidor selectivo de tirosin-quinasa (1) (2).

Tras su aprobación por diversas agencias reguladoras en 2001, Novartis AG inició su comercialización en Europa, Australia, América Latina, Estados Unidos, Canadá y Sudáfrica, de manera tal que en menos de dos años se convirtió en el tratamiento de primera línea para CML y posteriormente fue sumando indicaciones terapéuticas adicionales conforme se profundizó en sus propiedades farmacoló-

* Química Farmacéutica, Universidad Nacional de Colombia. Magíster en Ciencias Farmacéuticas (pendiente de grado), Universidad Nacional de Colombia. Contacto: lfdiazp@unal.edu.co

** Abogado, Universidad Nacional de Colombia, auxiliar de investigación Grupo de Investigación Plebio. Contacto: rfguevarap@unal.edu.co

*** Bióloga y magíster en Biología Universidad Nacional de Colombia, especialista en Propiedad Intelectual, Universidad Externado de Colombia. Asesora de patentes. Contacto: natalia.lamprea@gmail.com

**** Abogado, candidato a doctor en Derecho de la Universidad Nacional de Colombia. Máster en Propiedad Intelectual (Derecho de la Innovación, la Comunicación y la Cultura), Université-Paris Sud XI y Université Paris I-Panthéon Sorbonne. Profesor asociado de la Facultad de Derecho de la Universidad Nacional de Colombia y director del Grupo de Investigación plebio. Contacto: oalizarazoc@unal.edu.co Fecha de recepción: 11 de septiembre de 2016. Fecha de aceptación: 30 de noviembre de 2016. Para citar el artículo: Díaz-Pinilla, L. F., Guevara, R., Lamprea, N. y Lizarazo-Cortés, Ó. Caso Imatinib: análisis técnico y jurídico del trámite de patente en Colombia. Revista La Propiedad Inmaterial n.o 22, Universidad Externado de Colombia, julio-diciembre 2016, pp. 141-172. DOI: http://dx.doi.org/10.18601/16571959.n22.08. 
gicas, más aun al tener en consideración la facilidad asociada a su manejo al ser administrado por vía oral (3) (4).

En lo que respecta a temas de propiedad intelectual existe gran controversia en Colombia, dado que la patente concerniente a Glivec ${ }^{\circledR}$ se relaciona con una entidad polimórfica -denominada forma Beta $(\beta)$ - de una sal de la molécula original que fue objeto de solicitud de patente como entidad química en los años $1990^{[1]}$. Así las cosas, que Novartis AG haya optado por perseguir protección posterior para una entidad polimórfica de una sal del ya conocido Imatinib ha despertado una oleada de críticas en algunos sectores que se oponen a dicha patente, pues la consideran una mera extensión de la protección que carece del sustento técnico requerido para justificar su nivel inventivo. En este panorama se destaca la gran polémica suscitada en India, en donde la Corte Suprema se negó a otorgar patente al polimorfo $\beta$ debido a la falta de novedad y altura inventiva, teniendo en consideración que el Imatinib es una molécula ya conocida en el arte previo, y que el polimorfo $\beta$ no representa una mejora terapéutica comparativa frente al ya conocido $\alpha(5)$.

En el caso de Colombia, si bien la solicitud relacionada con el polimorfo $\beta$ del mesilato de Imatinib ha sido objeto de concesión tras una sentencia del Consejo de Estado (en adelante $\mathrm{CE}$ ), existen diversos sectores sociales que solicitaron la declaratoria de interés público con fines de licenciamiento obligatorio buscando aumentar la competencia y mitigar los altos precios asociados a dicho medicamento ${ }^{2}$.

De esta manera, resulta necesario analizar en profundidad los eventos que antecedieron a la concesión de patente en Colombia a la solicitud del polimorfo $\beta$-única patente relacionada con Imatinib en el territorio nacional-, toda vez que el trámite administrativo llevado a cabo ante la Superintendencia de Industria y Comercio (sIC) derivó en la negación de la solicitud -tanto en la presentación regular como en la interposición de recurso de reposición en vía gubernativa- en el año 2003, motivo por el cual el solicitante llevó el proceso ante el Consejo de Estado, quien en vía judicial y única instancia ordenó a la sIC revocar la negación y conceder la patente en 2012.

Se abordan los aspectos técnicos a lo largo del proceso de trámite de patentabilidad de la solicitud relacionada con la entidad polimórfica del mesilato de Imatinib -es decir, la forma $\beta$ de la sal-, con el fin de analizar tanto los motivos técnico-legales mediante los cuales la sic denegó dicha solicitud como aquellos argumentos tomados en cuenta por el CE para revocar dicha negación y ordenar la concesión de la patente a la farmacéutica Novartis AG.

1 EP0564409. Pyrimidin derivatives and process for their preparation. La solicitud en cuestión fue inicialmente presentada en el año 1993.

2 En el caso de Colombia, el Ministerio de Salud y Protección Social emitió en febrero de 2015 la Resolución 354 de 2015, "Por la cual se inicia una actuación administrativa para el estudio de la declaratoria de existencia de razones de interés público para someter a la patente del medicamento imatinib, a licencia obligatoria”. Toda la información de esa actuación administrativa está disponible en: https:/www.minsalud.gov.co/salud/MT/ Paginas/medicamentos-propiedad-intelectual.aspx Última consulta, 16 de octubre de 2016. 
El análisis muestra que la sic en su negación de la solicitud desestimó el reconocer el "esfuerzo técnico" que requiere la obtención de un polimorfo, y el cE, por su parte, inclinado por el concepto de los dos expertos que actuaron como testigo y perito, solo se enfocó en el esfuerzo técnico, entendido como la necesidad de experimentación, pero no valoró el requisito de patentabilidad del nivel inventivo de la forma polimórfica, específicamente si el esfuerzo técnico logra un efecto sorprendente e inesperado.

\section{Metodología}

Se realizó un análisis interdisciplinario, no sólo de las resoluciones de la sic y la sentencia del CE, sino de los expedientes de la actuación administrativa en digital ${ }^{3}$ y el proceso judicial en físico ${ }^{4}$, haciendo énfasis en sus piezas más relevantes, entre otras: las reivindicaciones, el testimonio, el peritazgo y los alegatos de conclusión presentados por la sic. También se revisaron documentos relacionados con el caso, como las respuestas a derechos de petición presentados a la sIC donde se solicitaba aclaración sobre el alcance de la patente y la actuación de la entidad en la demanda ante el CE. Más que expresar una posición absoluta o general sobre la patentabilidad o no de polimorfos, se indican de forma descriptiva y objetiva algunos de los argumentos técnicos y jurídicos a favor y en contra de la patentabilidad en este caso específico. No se analiza en profundidad la solicitud de declaratoria de interés público (en adelante DIP) con fines de licencia obligatoria (LO) presentada por ONG el 24 de noviembre de 2014, puesto que no hace parte del trámite de patente aquí analizado y, además de aspectos técnicos y jurídicos, presenta complejidades económicas.

\section{Estado ACTUAL DE LA DEClaratoria DE INTERÉS PÚblico DEl IMATINiB EN Colombia}

El 17 de febrero de 2016 un comité le recomendó al Ministerio de Salud declarar de interés público el medicamento, pero previamente explorar una etapa de negociación con Novartis. Dicha negociación inició el 12 de abril de 2016, pero el gobierno y la empresa no llegaron a un acuerdo. Luego, en junio de 2016, el gobierno expidió la DIP, pero con fines de fijación de precio excepcional, no de LO (Res. 2475 del 14 de junio de 2016)5.

3 sic, trámite: http://serviciospub.sic.gov.co/Sic2/Tramites/Radicacion/Radicacion/Consultas $/$ ConsultaRadicacion.php? buscando $=$ radi $\& v a n o=98 \& v n u m=38983 \& v c o n=\% 20 \% 20$ \&vcos=6\&vtemaa $=6$ Expediente: http://serviciospub.sic.gov.co/ $\sim$ oparra/serv_57/externas/ DetallePatente.php? consultando $=$ patentescolombianas $\&$ parametros $=$ opparametros $\&$ vano $=$ $98 \&$ vtra $=2 \&$ vnum $=38983 \&$ vcon $=\% 20 \% 20 \& v$ cons $=0 \& v$ vre $=14114 \&$ vtem $=Q F$

4 Consejo de Estado, exp. 11001-03-24-000-2003-00508-01, disponible en: http:// consejodeestado.gov.co/consultasexternas.php

5 Resolución 2475 del 14 de junio de 2016, disponible en: https://www.minsalud.gov. $\mathrm{co} / \mathrm{sites} / \mathrm{rid} /$ Lists/BibliotecaDigital/RIDE/DE/DIJ/Resolucion-2475-de-2016.pdf 
En septiembre de 2016 el Ministerio de Salud respondió los recursos de reposición presentados por las ONG y por Novartis AG. En las resoluciones 4002 y 4148 del mismo año confirmó la DIP para fijación de precios. Es decir, no accedió a la pretensión de Novartis AG de revocar la declaratoria y en su lugar rechazar la emisión de la DIP, y tampoco accedió a que la DIP fuese para Lo como lo pedían las ONG, aunque voceros de estas han declarado que no descartan ir a la SIC para intentar una LO con base en la DIP. Adicionalmente, gremios como PhrMA, EFPIA, BIO, Afidro, U.S. Chamber of Commerce, etc. solicitaron al Ministerio de Salud revocar la DIP de Imatinib.

Posteriormente, el 14 de septiembre de 2016 se publicó en el sitio web del Ministerio de Salud un proyecto de Circular de la Comisión Nacional de Precios de Medicamentos y Dispositivos Médicos, "por la cual se establece una Metodología que regule precios de medicamentos en situaciones excepcionales en las que se haya declarado el interés público", y se recibieron comentarios hasta el 27 de septiembre. El 21 de octubre el Ministerio de Salud anunció que el precio se reduciría en más de un $40 \%$, pasando de 350 a 206 pesos colombianos por miligramo. Dicha Circular General n. ${ }^{\circ} 03$ de 2016 se publicó en el Diario Oficial el 22 de noviembre de 2016. $\mathrm{Al}$ momento de hacer la revisión final de este artículo se conocía el borrador de la Circular 04 que aplica esa metodología de situaciones excepcionales al Imatinib. Es decir, 24 meses después de que se expidiera la Circular 04 para materializar la fijación del precio. Esto muestra las complejidades y limitaciones que enfrentan los trámites de Lo. Además, sugiere que pese a las controversias y visibilidad mediática que generan, su efecto concreto en la competencia es bastante reducido, claro está, sin desconocer la actuación administrativa realizada, los esfuerzos de los participantes, y los posibles efectos simbólicos y de imagen que puede tener el procedimiento administrativo de la DIP. La DIP de Imatinib en Colombia y el intento de obtener una Lo son mencionados en un reporte de Naciones Unidas (6) divulgado el 14 de septiembre de 2016, particularmente en un apartado titulado "Limitaciones para usar las flexibilidades de ADPIC", que entre otras describe algunos de los retos y presiones existentes.

Lo anterior, en parte, puede ser un argumento adicional para reafirmar la importancia de la calidad en el examen de patentes secundarias tanto por vía administrativa como por vía judicial. El rigor en el examen de patentes recibe menos atención, pero puede ser más relevante que las Lo. El impacto mediático de la DIP para LO puede incidir en alguna medida en que se les preste menos atención a otras medidas importantes como buscar que algunos criterios de la oficina de patentes sean más estrictos, así como implementar el artículo 70 de la Ley 1753 consistente en que el Ministerio de Salud haga comentarios no vinculantes durante el trámite de las solicitudes de patente. Además, el despliegue noticioso de un caso excepcional como Imatinib puede hacer perder de vista que en 2015 en Colombia se presentaron 2.242 solicitudes de patente de invención, de las cuales alrededor de 630 son del campo farmacéutico (7). 
De otra parte, un año después de la solicitud de DIP para Imatinib, en octubre de $2015^{[6]}$, se presentó la tercera solicitud de Dip con fines de Lo en Colombia, en ese caso para medicinas contra hepatitis C. A noviembre de 2016 no se había iniciado el trámite administrativo de esa petición; el gobierno posiblemente prefirió concentrarse en Imatinib, en otras políticas de control de precios, y resolver primero esos temas anteriores. Además, quizá se quieren evitar las presiones que generaría tramitar dos solicitudes de DIP o afines simultáneamente, lo que sugiere otras dificultades para emplear las flexibilidades de los ADPIC.

\section{AspeCtos TÉCNICOS DEL CASO}

\section{A. Descripción téCNiCa de la solicitud de patente Radicada eN LA SUPERINTENDENCIA DE INDUSTRIA y COMERCIO}

La solicitud de patente relacionada con Imatinib en Colombia se encuentra referida específicamente a una forma cristalina del mesilato de Imatinib (correspondiente a la forma $\beta$ ), y no a la entidad química propiamente dicha. En este sentido, es importante considerar que la solicitud de patente que contempla la molécula de Imatinib como materia esencial de una invención corresponde a la solicitud europea EP0564409 concedida en el año 2000, la cual de manera general describe moléculas derivadas de pirimidina que se ajustan a la siguiente fórmula general de acuerdo a una invención tipo Markush:

Figura i: Fórmula I, CORRESPONDIENTE A LA SOliCitud DE PATENTE EPo564409.

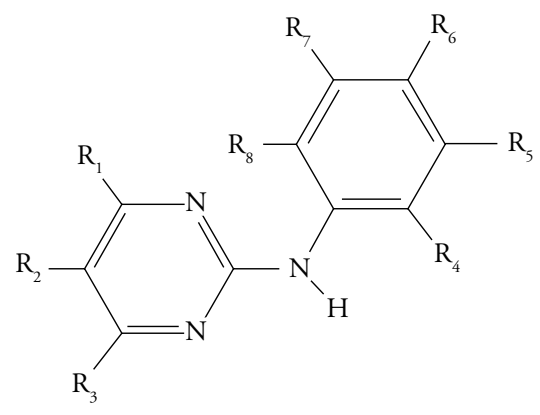

El alcance de esa patente incluye la molécula de Imatinib ${ }^{7}$ y sus sales farmacéuticamente aceptables. Tal solicitud fue adicionalmente presentada y concedida en

6 "Solicitud de declaratoria de interés público para el acceso al tratamiento con antivirales de acción directa en hepatitis C”, presentada el 28 de octubre de 2015 por unas ONG, disponible en: http://web.ifarma.org/images/files/hepc.pdf

7 Formula molecular correspondiente a 4-(4-metilpiperazin-1-ilmetil)-N-[4-metil-3-(4piridin-3-il)pirimidin-2-ilamino-fenil] benzamida. 
otras oficinas de patentes, tales como la Oficina de Patentes y Marcas de Estados Unidos $^{8}$ y la Oficina Australiana de Patentes ${ }^{9}$, jurisdicciones en las cuales o bien ya caducó o está próxima a hacerlo. Sin embargo, en Colombia dicha solicitud de patente inicial no fue presentada, por lo que la molécula original está en el dominio público.

Ante este panorama, Novartis AG incluyó dentro de su estrategia de gestión de PI la generación de solicitudes de patente adicionales relacionadas con el Imatinib, en términos de uso, tratamiento, modificaciones farmacotécnicas de la formulación, o modificaciones del compuesto inicial, de manera que la protección abarcara el mayor espectro posible. Así, Novartis AG presentó en 1998, ante la sIC, solicitud de patente bajo el título "Modificación de cristal de un derivado de n-fenil-2-pirimidinamina, procesos para su fabricación y su uso", que, en esencia, buscaba protección para la forma cristalina $\beta^{10}$.

De esta manera, dicha solicitud reconoce como antecedente la existencia de la solicitud europea EP0564409. Sin embargo, el capítulo descriptivo establece enfáticamente que la novedad y nivel inventivo de la materia contenida reside en la identificación de una forma cristalina del mesilato de Imatinib que cuenta con propiedades físicas y farmacotécnicas de interés, asociadas particularmente a la forma de los cristales y sus propiedades de flujo "altamente deseadas" que favorecen el almacenamiento y procesamiento de la materia prima, y la formulación de la misma en una forma farmacéutica sólida, es decir, el cristal $\beta$. Por tanto, las ventajas señaladas corresponden a aspectos de utilidad en los procesos de fabricación y formulación, pero no se asocian con un avance en la terapéutica.

En este sentido, la solicitud de patente incluye información técnica asociada a las propiedades de la forma cristalina $\beta$, tales como forma, pureza, punto de fusión, higroscopicidad, análisis de diagramas de difracción de rayos $\mathrm{X}$, y compara dichos valores con los obtenidos por la forma cristalina típicamente encontrada para la sal mesilato -es decir, la forma cristalina $\alpha$-, exponiéndose las ventajas asociadas al polimorfo objeto de protección. No obstante, alude que las propiedades farmacológicas del polimorfo descrito son las mismas propiedades farmacológicas conocidas para Imatinib.

Ahora bien, el capítulo reivindicatorio que fue objeto de concesión -por orden del $\mathrm{CE}-$ contiene trece reivindicaciones, con dos reivindicaciones independientes (producto y proceso), dentro de las cuales la número 1 hace mención de las propiedades diferenciales de la sal de adición de ácido metansulfónico en modificación $\beta$-en términos de difracción de rayos $X-$, y sus respectivas reivindicaciones dependientes 2 a 9 refieren aspectos técnicos adicionales relacionados con la caracterización fisicoquímica de dicha forma cristalina; la reivindicación 10 alude al uso de la forma cristalina de la sal de adición analizada para el diagnóstico 
o tratamiento terapéutico de humanos o animales; la reivindicación 11 se refiere a una composición farmacéutica que contiene el principio activo objeto de la invención; la reivindicación 12 protege el uso de sal de adición para la preparación de agentes farmacológicos para el tratamiento de una enfermedad tumoral, y la reivindicación 13 se asocia con procesos para la preparación de la forma cristalina $\beta$. Así pues, las reivindicaciones 10 y 12 son materia no patentable por la legislación colombiana (Decisión Andina 486 de 2000 -en adelante Dec. 486/2000-, arts. 14 y 21, y 20 lit. d).

\section{B. Trámite de la solicitud de patente en Colombia}

Tal como se expuso inicialmente, el proceso de solicitud de patente asociada a Glivec $^{\circledR}$ en Colombia se resume en los siguientes hechos:

(i) Presentación inicial ante la sic, en el año 1998, de la solicitud de patente de invención 98-038983, bajo el título "Modificación de cristal de un derivado de n-fenil-2-pirimidinamina, procesos para su fabricación y su uso";

(ii) Negación de patente por parte de la sic mediante Resolución 04164 del 25 de febrero de 2003;

(iii) Confirmación de negación de la patente mediante Resolución 16268 del 16 de junio de 2003 por la sIC, tras interposición de recurso de reposición por parte del solicitante, $y$, por tanto, terminación del trámite administrativo del expediente asociado;

(iv) Presentación de demanda de nulidad y restablecimiento del derecho por el solicitante ante el Consejo de Estado, en 2003, bajo expediente número 200300508 .

(v) Declaración de nulidad de las resoluciones 04164 del 25 de febrero de 2003 y 16268 del 16 de junio de 2003, por parte del Consejo de Estado en 2012, y orden a la sic de emitir la concesión del derecho de patente a la invención en cuestión; y

(vi) Concesión de patente a las reivindicaciones 1 a 13 de la solicitud mediante Resolución 24250 del 25 de abril de 2012 de la sic. Es importante mencionar que en esta etapa ni el CE ni la sic hicieron comentarios a las reivindicaciones, y las mismas se concedieron en la última versión del expediente existente antes de febrero de 2003, sin objetar reivindicaciones como la 10 y la 12 que, como se indicó, no son materia patentable bajo la Decisión 486.

Así las cosas, el trámite asociado a la solicitud de patente resultó polémico en Colombia debido a que la sic, a lo largo del trámite administrativo (1998-2003), mantuvo su posición frente a la imposibilidad de otorgar la patente a la forma cristalina $\beta$ del mesilato de 4-(4-metilpiperazin-1-ilmetil)-N-[4-metil-3-(4-piridin3-il)pirimidin-2-ilamino-fenil]benzamida al considerar que las reivindicaciones 1 a 13 carecían de nivel inventivo $^{11}$; y por su parte el CE, en respuesta a la demanda 
presentada por el solicitante, avaló la argumentación que defiende el nivel inventivo asociado al polimorfo revelado por la solicitud de patente. Por tal razón, resulta adecuado considerar los aspectos de carácter técnico que motivaron las decisiones de dichas entidades.

\section{ANÁlisis téCNico lleVAdo a Cabo POR La Superintendencia De Industria y Comercio}

Teniendo en consideración que la solicitud de patente presentada ante la sic en el año 1998 establece que el polimorfo $\beta$ resulta superior al polimorfo $\alpha$ en términos de sus propiedades farmacotécnicas -es decir, aquellas propiedades de las materias primas que se deben considerar en el proceso de diseño y formulación de productos farmacéuticos-, tales como forma de los cristales obtenidos, higroscopicidad y características de flujo del sólido, y de su estabilidad termodinámica superior, pero no se atribuyen propiedades farmacológicas diferenciales al mismo ${ }^{12}$, y, por ende, el mismo no se constituye como una alternativa terapéutica superior en comparación con el ya conocido Imatinib, la sic emitió un primer examen técnico de fondo el 15 de agosto de 2002, en el cual afectó la claridad de la solicitud, señalando que debía definirse en mayor medida el cristal revelado por la reivindicación 1 en función de las características propias que lo diferencian del arte previo, y el nivel inventivo, al considerar que el arte previo identificado -es decir, las solicitudes de patente EP0564409 y US5521184, y el libro de texto Farmacia de Remington- ya contemplaban la viabilidad de generar sales del compuesto, a partir del empleo de ácidos ampliamente conocidos, tales como los derivados del ácido sulfónico.

En este sentido, para la sic las enseñanzas del libro Farmacia de Remington -referidas a las labores implícitas en la formulación de productos farmacéuticos- bastarían para comprender que es indispensable la determinación inicial de la existencia de una o más formas cristalinas de un compuesto -en términos de conocer la vía para la obtención de cada polimorfo-, sus propiedades y ventajas ${ }^{13}$. Por tanto, en concepto de la sic, la materia reclamada correspondía al resultado de un evento comúnmente ejecutado en la práctica farmacéutica, el cual al ser de conocimiento general en el campo técnico y al no aportar ningún efecto técnico especial, no superaría el requisito de altura inventiva.

En respuesta a lo anterior, el solicitante modificó el pliego reivindicatorio con miras a profundizar en las propiedades particulares del cristal revelado, mediante inclusión de los valores de ángulos de refracción $2 \Theta$ que describen el patrón característico del cristal en un diagrama de difracción de rayos X; lo anterior corresponde a una técnica analítica altamente empleada para diferenciar las formas cristalinas

processes for the preparation thereof), publicadas en 1993 y 1996 , respectivamente, y el libro Farmacia de Remington, publicado en 1995.

12 sic, exp. 98-38983, fls. 17 y 18.

13 sic, Res. 4164 de 2003. 
de un compuesto mediante el aprovechamiento del fenómeno físico existente entre un haz de rayos $\mathrm{X}$ y la estructura de un sólido cristalino. Así mismo, reiteró que la ausencia de información en el arte previo relacionada con el polimorfo específico $(\beta)$ del compuesto contemplado por la invención constituye motivación suficiente para reconocer el nivel inventivo de las reivindicaciones, ya que las solicitudes EP0564409 y US5521184 son ajenas a la generación específica de la sal mesilato de dicho compuesto, y que el libro citado desconoce los aspectos asociados a la obtención de la entidad polimórfica $\beta$ reivindicada, y por ende no contempla los efectos técnicos benéficos asociados a la misma ${ }^{14}$.

En este sentido, la sic emitió un nuevo examen técnico de fondo el 23 de diciembre de 2002, ratificando su posición frente al análisis de nivel inventivo llevado a cabo previamente. De manera adicional, la sic requirió la inclusión de parámetros adicionales a los datos del diagrama de difracción de rayos $\mathrm{X}$ para poder evaluar el nivel inventivo del polimorfo. A continuación se incluye textualmente la reivindicación 1 , tal como fue modificada por el solicitante durante el proceso de examen de patentabilidad en noviembre de 2002:

Una forma de la sal de adición de ácido metansulfónico de un compuesto de la fórmula I<smiles>Cc1ccc(NC(=O)c2ccc(CN3CCN(C)CC3)cc2)cc1Nc1nccc(-c2cccnc2)n1</smiles>

que comprende por lo menos $90 \%$ por peso de cristales de la modificación $\beta$, dichos cristales de la modificación $\beta$ están caracterizados por un diagrama de difracción de rayos $\mathrm{X}$ que muestra una intensidad de línea relativa de $20 \%$ o más al compararse con la línea más intensa en el diagrama a los siguientes ángulos de refracción 2 teta: $9.7^{\circ}$, $13.9^{\circ}, 14.7^{\circ}, 17.5^{\circ}, 18.2^{\circ}, 20.0^{\circ}, 20.6^{\circ}, 21.1^{\circ}, 22.1^{\circ}, 22.7^{\circ}, 23.8^{\circ}, 29.8^{\circ}$ y $30.8^{\circ}$.

Finalmente, la sic consideró que la reivindicación 13 -referida al proceso de obtención de la forma cristalina- carecía de nivel inventivo al referirse a un proceso muy general y ampliamente conocido en el arte previo $^{15}$.

Así pues, la sic emitió concepto final mediante Resolución 04164 del 25 de febrero de 2003, negando el privilegio de patente de invención al considerar que la misma resulta obvia a la luz del arte previo por las razones expuestas.

Ahora bien, frente a la negación de la sic el solicitante presentó recurso de reposición el 8 de abril de 2003 para solicitar el reconocimiento del nivel inventivo 
de las reivindicaciones 1 a 13 teniendo en cuenta que el alcance de estas es desconocido por el arte previo -lo cual aleja al versado en la materia de llegar de manera obvia-, y que como prueba de ello dichas reivindicaciones habían sido reconocidas como patentables por una autoridad internacional -en el correspondiente Informe de Examen Internacional Preliminar-, a saber, la Oficina Japonesa de Patentes (JPO por sus siglas en inglés) y la Oficina de Patentes peruana (INDECOPI).

No obstante, lo anterior, la sic emitió una nueva resolución -16268 del 16 de junio de 2003- ratificando la decisión de negación previamente emitida, haciendo uso de la misma argumentación empleada a lo largo de los exámenes técnicos.

Partiendo de lo anterior se evidencia que, si bien la sic reconoció la novedad de la materia reivindicada, enfatizó en la ausencia de nivel inventivo de la solicitud argumentando que la misma perseguía protección para una forma cristalina de una molécula ya conocida en el arte previo, y por tanto aparentemente se partió del hecho de que el solicitante buscaba protección para una aplicación práctica de materia ya conocida en el estado de la técnica.

De esta manera,

... al considerar que para reconocer el nivel inventivo de materia que se constituye como una alternativa a materia ya conocida se requeriría de la demostración de efectos técnicos superiores o inesperados que supongan un avance en el campo técnico -y no la mera modificación de tal elemento con miras a obtener resultados ya conocidos-, lo cual, en concepto de la sIC, no procedió en el presente caso toda vez que:

(i) no existe ninguna diferencia en términos de actividad farmacológica (terapéutica) entre la materia reivindicada y la materia ya conocida en el arte previo, y

(ii) si bien el polimorfo objeto de la solicitud no es conocido como tal en el arte previo, las propiedades fisicoquímicas y farmacotécnicas atribuidas al mismo se consideran el resultado de actividades propias del proceso de formulación de productos farmacéuticos y, por ende, los mismos son el resultado de investigación dirigida por las enseñanzas propias del campo técnico, que por más exhaustiva o extensa que resulte es de dominio general, y por ende sus resultados pueden ser considerados obvios ${ }^{16}$.

\section{EsFueRZO TÉCNICO vs. EFECTO TÉCNICO EN ESTUdIO DE NIVEL INVENTIVO}

Una vez expuestos los aspectos técnicos relacionados con el presente caso, se analizará desde la perspectiva de la química farmacéutica la pertinencia de la argumentación dada tanto por la sic como por los expertos -Dr. Sutter y Dr. Henao- durante la etapa de litigio ante el CE en lo referido a la factibilidad y dificultad asociadas a la obtención e identificación de entidades polimórficas a partir del conocimiento de un compuesto de interés. Lo anterior, con el fin de evidenciar 
los aspectos que influyeron en la patentabilidad en Colombia del polimorfo $\beta$ del mesilato de 4-(4-metilpiperazin-1-ilmetil)-N-[4-metil-3-(4-piridin-3-il)pirimidin2-ilamino)fenil]benzamida. En este respecto, debe considerarse que la posición de los expertos asociados al proceso de demanda se basó enteramente en el esfuerzo técnico relacionado con la obtención de entidades polimórficas ${ }^{17}$.

El polimorfismo se define como la habilidad que posee una sustancia de existir en varias formas cristalinas con una diferente disposición espacial de las moléculas que forman el cristal, es decir, consecuencialmente, las distintas formas cristalinas de un mismo compuesto cuentan con diferentes propiedades físicas en fase sólida, pero se comportan de igual manera en disolución debido al hecho de que cada forma cristalina tiene una estructura única y se trata, por tanto, de un material con propiedades físicas y químicas propias (8) (9).

Dentro de las técnicas comúnmente empleadas para la obtención de materias primas de alta pureza se destaca la cristalización, y a ella va ligado el estudio de las diferentes conformaciones cristalinas potencialmente obtenidas durante el proceso. En este sentido, la técnica de difracción de rayos X es altamente empleada con propósitos de caracterización polimórfica pues permite la elucidación estructural de las moléculas en la red cristalina, haciendo posible obtener un patrón único característico para cada cristal (8) (9).

Por tanto, el estudio de conformaciones cristalinas permite evaluar la conformación más idónea para hacer parte de una formulación farmacéutica, en términos de las propiedades farmacocinéticas del principio activo -en particular aquellas relacionadas con la absorción de dicho ingrediente activo al ser administrado a un sujeto- con el fin de asegurar que el proceso de formulación resultará en la incorporación de una materia prima estable, idónea para su administración en humanos y con potencial terapéutico adecuado (10).

Con base en lo anterior, si bien resulta lógica la necesidad de estudiar las diversas entidades polimórficas de un principio activo, dicha etapa es un paso obligado en el diseño y desarrollo de nuevos medicamentos que no puede obviarse ni, mucho menos, basarse en suposiciones teóricas, sino que requiere de una debida labor de investigación de laboratorio que, como se dijo anteriormente, se encuentra inmersa en las actividades rutinarias de los procesos de formulación.

En este sentido, el abordaje de la sic minimizó la importancia del estudio y obtención de polimorfos al asumir que dichas etapas se constituyen como una práctica elemental que no requiere ningún tipo de esfuerzo técnico riguroso. Así pues, si bien el compuesto 4-(4-metilpiperazin-1-ilmetil)-N-[4-metil-3-(4piridin-3-il)pirimidin-2-ilamino)fenil]benzamida cae dentro del alcance de las anterioridades citadas, estas no proporcionan enseñanzas o sugerencias relacionadas con la existencia de entidades polimórficas de alto interés para el ámbito farmacéutico, tales como el polimorfo $\beta$ de la sal mesilato, y por ende llegar a la 
obtención de dicho cristal requiere un esfuerzo investigativo considerable (aunque no necesariamente ese esfuerzo implique cumplir el requisito de patentabilidad de nivel inventivo). Lo anterior se suma a los beneficios técnicos ya descritos para dicho polimorfo.

Por su parte, la anterioridad correspondiente al libro Farmacia de Remington corresponde a un documento de carácter básico en el campo técnico, que si bien aborda aspectos generales para la obtención e identificación de polimorfos, no puede afectar la patentabilidad de una invención per se habida cuenta de su naturaleza general. Debe recordarse que en el análisis de nivel inventivo el documento citado debe resolver el problema técnico objetivo planteado, y en este caso en particular, al ser conocida la molécula química del Imatinib, el segundo documento debía dar información relevante para la obtención del cristal; en este sentido, si dicho libro de texto fuera empleado para la ejecución de análisis de nivel inventivo debido a la materia que contiene, resultaría difícil que el mismo no encajara en la gran mayoría de invenciones de la química farmacéutica.

Ahora bien, la argumentación tomada en consideración por parte del CE está estrechamente relacionada con la existencia de un esfuerzo técnico, pero no ahonda de manera contundente en el efecto técnico alcanzado, más allá de las preguntas consignadas a lo largo del cuestionario de peritazgo que indagaba si las anterioridades citadas permitían llegar a la obtención del polimorfo $\beta$. En este sentido, debe considerarse que el cuestionario -redactado por la sociedad demandante- se encuentra diseñado para emitir un concepto favorable en relación con el esfuerzo investigativo asociado a la invención, de manera que al responder el mismo se haga hincapié en dicho esfuerzo técnico sin ahondar en un análisis del efecto técnico sorprendente, que es un requisito fundamental para valorar el cumplimiento del nivel inventivo, tal como es requerido por la Decisión 486, artículos 14 y 18. Lo anterior puede corroborarse en diversos fragmentos de la Sentencia del CE, tanto en el testimonio de Bertrand Sutter como en el dictamen pericial técnico rendido por José Antonio Henao Martínez ${ }^{18}$. Por ejemplo, en la pregunta 6 del cuestionario: "Diga el señor perito si de acuerdo con el estado de la técnica en química se requeriría investigación de laboratorio para conocer con certeza el mencionado comportamiento de un polimorfo".

Así las cosas, se estima que el análisis técnico llevado a cabo tanto por la sic como por el CE puede considerarse deficiente a la hora de evaluar en profundidad si la invención asociada al caso Imatinib cumplía o no el requisito de nivel inventivo, pues la argumentación giró en torno a la existencia -o ausencia- de un esfuerzo técnico razonable para la obtención del polimorfo $\beta$.

Ahora bien, además de las cuestiones previamente esbozadas acerca de la validez, en términos de análisis de patentabilidad, de los argumentos esbozados por ambas 
entidades, resulta de interés particular preguntarse acerca de la valoración de nivel inventivo sobre la que se basó el caso, en el sentido de cuestionar, ¿cuál es la línea que separa la existencia de un esfuerzo técnico o investigativo de la existencia de nivel inventivo?, o si ¿todo resultado de un proceso investigativo, entendido como una experimentación, merece el calificativo de invención, y, por ende, debe ser objeto de patente? En otras palabras, la experimentación puede ser un componente de la investigación requerido para llevar a cabo una invención, pero no siempre hay nivel inventivo por el sólo hecho de haber realizado experimentación. Tales cuestionamientos resultan de especial interés en la coyuntura actual del sistema de PI en donde se ha evidenciado, de manera particular, que las prácticas de innovación de la industria farmacéutica han venido siendo objeto de modificación en términos de disminución de la investigación dirigida al descubrimiento y/o desarrollo de nuevos fármacos -los cuales son considerados como "invenciones de primera generación"-, y en su lugar ha habido un aumento de los esfuerzos asociados al mejoramiento, modificación o búsqueda de aplicaciones adicionales para fármacos ya conocidos, es decir, las denominadas "invenciones de segunda generación”, que entre otras modalidades incluyen invenciones de selección, isómeros ópticos, polimorfos, metabolitos, profármacos, segundos usos y métodos de tratamiento (11).

Partiendo de dicha tendencia, es innegable la existencia de un acalorado debate entre quienes apoyan la protección amplia de tales "invenciones de segunda generación", por considerar que la patentabilidad de las mismas constituye un incentivo para el mejoramiento continuo y la inversión, y sus detractores, quienes consideran que la solicitud de derechos de patente asociada a tales invenciones frecuentemente resulta ser una mera estrategia para extender la protección, y así evitar la finalización de los DPI previamente obtenidos, lo cual, en lugar de incentivar la innovación, incentiva el monopolio de las grandes compañías que buscan eliminar o retrasar la competencia que representa el mercado de los genéricos (11).

Por ende, aun cuando es claro que las posiciones de las diferentes oficinas de patentes alrededor del mundo -incluyendo la sic- pueden variar acorde a las políticas de PI de cada nación, resulta interesante ver cómo, para este caso específico, en Colombia, las posiciones o interpretaciones de dos entidades estatales resultan contradictorias a sabiendas de que el análisis de patentabilidad debe hacerse bajo la misma legislación.

Vale aclarar en este punto que a partir de 2012, con la publicación de la "Guía de examen de solicitudes de patente de invención y modelos de utilidad" emitida por la sic, la posición de esta entidad respecto al estudio de los polimorfos ha cambiado, y ahora se suele aceptar la novedad de estos compuestos y se realiza un examen estrictamente dirigido a evaluar el nivel inventivo, generalmente evaluando si la mayor solubilidad o biodisponibilidad del polimorfo se considera un efecto técnico sorprendente. 
Lo anterior no implica que la totalidad de solicitudes relacionadas con entidades polimórficas estén siendo objeto de concesión por parte de la sic, pero sí que el campo de análisis ha sufrido modificaciones considerables que alteran y amplían el panorama de presentación y aceptación de dicho tipo de solicitudes en nuestro país. Dicho asunto merece un análisis objetivo más profundo que excede el espacio y propósito de este artículo.

\section{Aspectos JuRÍdicos Del CASO}

\section{A. Análisis jurídico llevado a cabo por el Consejo de Estado}

Ahora bien, en lo que respecta a la acción de nulidad y restablecimiento del derecho interpuesta por Novartis AG contra las resoluciones de la SIC - por la negación de la patente- ante el CE, es importante resaltar que se otorgó validez a la misma argumentación presentada por la demandante a lo largo del trámite administrativo, y de manera particular la sentencia del CE se basó en las declaraciones de dos expertos en el campo técnico quienes se desempeñaron como tales durante el proceso. De manera adicional, se anexaron certificados de patentes foráneos.

En este sentido, resulta imperativo profundizar en la idoneidad de los expertos (perito y jueces), los argumentos esbozados por los mismos y las razones jurídicas que motivaron las interpretaciones, con el fin de evidenciar los posibles aciertos y desaciertos de los jueces en relación con el proceso al dictaminar la nulidad de la decisión de la sic y, con esto, permitir la concesión final de la patente asociada al Imatinib.

\section{Aspectos sustanciales}

La negación de la solicitud de patente se basó en la falta de nivel inventivo, por lo que es necesario tener presente un esquema conceptual bajo el cual evaluar los hechos objeto de la presente controversia.

En nuestra legislación, la altura inventiva está definida por el artículo 18 de la Decisión 486 de la Comunidad Andina de Naciones (CAN) así: "Se considerará que una invención tiene nivel inventivo, si para una persona del oficio normalmente versada en la materia técnica correspondiente, esa invención no hubiese resultado obvia ni se hubiese derivado de manera evidente del estado de la técnica”. El procedimiento de análisis del nivel inventivo no es igual en todas las jurisdicciones y ostenta un tratamiento diferenciado de acuerdo a las directrices de análisis establecidas en la oficina de patentes a la cual nos refiramos (12). Así pues, cada jurisdicción ejerce soberanía sobre la estructura jurídica y procedimental a seguir para el examen y concesión o negación de patentes. 
A propósito de los ítems que caracterizan el nivel inventivo, se hace referencia al nivel de especialización del evaluador, en este caso, una persona versada en la materia que posee los conocimientos medios de su trabajo, quien, ubicada en un contexto imaginario de comprensión de los textos puestos a disposición del público que tratan sobre la materia que se busca patentar, no hubiese establecido con claridad el camino a seguir para crear la invención; en otras palabras, la negativa de la solicitud "depende de operaciones mentales que no ameritan mayor esfuerzo $y$, por tanto, no merecen la protección" (13).

Así mismo, la apreciación del nivel inventivo debe seguir el método de acercamiento problema-solución, que según el Tribunal Andino de Justicia (TJCA) se delimita en:

a) identificar el estado de la técnica más próximo a la invención reivindicada; b) evaluar los resultados (o efectos) técnicos obtenidos por la invención reivindicada en relación con el estado de la técnica más próximo; c) examinar si, de conformidad con el estado de la técnica más próximo, el experto en la materia habría o no propuesto las características técnicas que distinguen la invención reivindicada ${ }^{19}$.

En razón de lo expuesto, determinados los elementos necesarios en la interpretación de la concesión de una patente, la misma extenderá lo necesario para hacerse acreedora de tal derecho cuando "[l]a invención alcanza un resultado sorprendente o inesperado. Siempre que una invención logre un resultado que no se esperaba, en la solución que se buscaba existe nivel inventivo, toda vez que se trata de un imprevisto que caracteriza el estado de la técnica" (Lizarazo-Cortés y Lamprea, 2014, p. 211). A partir de lo anterior, la altura inventiva no puede ser valorada bajo el esfuerzo logístico o pecuniario necesario para llegar a la solución planteada, pero si el tipo de razonamiento utilizado es no evidente y además soluciona el vacío presentado en la técnica, entonces tendrá mérito para ser patentada.

\section{Aspectos probatorios}

La prueba, como elemento más próximo del que hace uso el juez para fundamentar su fallo, presupone que esta debe ser observada bajo ciertos parámetros y lineamientos (pertinencia, conducencia y utilidad); así mismo, dada la fecha del caso y del proceso judicial, estos juicios deben ser valorados teniendo en cuenta el Código de Procedimiento Civil (CPC), de suerte que ciertos comentarios serán presentados en relación con la valoración

19 Tribunal Andino de Justicia, Interpretación prejudicial, Proceso 41-IP-2006, disponible en: intranet.comunidadandina.org/Documentos/Procesos/41-IP-2006.doc Consultado en $10 / 11 / 2015$. 
probatoria y los aspectos sustanciales ya enunciados en anteriores párrafos. Sin perjuicio de lo anterior, se harán alusiones al CGP cuando corresponda.

Respecto a la valoración probatoria, nuestro sistema jurídico contempla ciertos principios que no se pueden perder de vista, entre ellos el de la conducencia, que hace referencia a "la idoneidad legal que tiene un medio de prueba para demostrar un hecho y surge de la comparación entre la ley y el medio de prueba empleado o a emplear, a fin de establecer si el hecho -materia de litigio- se puede demostrar con el empleo de ese determinado medio de prueba" $(14$, p. 95$)$.

Bajo esta perspectiva, la prueba debe contar con la capacidad de llevar conocimiento al juez sobre el hecho a decidir. No toda prueba tiene la aptitud de poder demostrar una circunstancia, de tal modo que los medios probatorios aportados deben tener esa relación con la controversia para ilustrar al juzgador sobre las aristas y aspectos relevantes en el proceso.

La pertinencia probatoria es otro principio importante en nuestro sistema, y "consiste en la relación lógica o jurídica entre el medio de prueba y el hecho materia de la prueba; el medio de prueba debe tener una relación directa con el hecho objeto de la investigación o del litigio" (14, p. 94); los citados presupuestos permiten al juez apartar su vista de aportes probatorios que puedan resultar irrelevantes. En este sentido, tanto el aporte probatorio de la contestación de demanda en un proceso distinto adelantado ante la SIC, como también los certificados de patentes emitidos en otras jurisdicciones, no cumplen tales requisitos, debido a las diferencias entre los sistemas legales que valoran este tipo de solicitudes, así como al carácter soberano de cada oficina de patentes, lo que manifiesta la impertinencia de tal medio probatorio para llevar conocimiento al juez respecto de la patentabilidad del polimorfo, ya que los análisis fueron realizados con base en otras normas.

En segundo lugar, y a título de crítica, evidenciamos que el aporte de la prueba documental de contestación de demanda radicada por la sic en un proceso donde también se discutía sobre polimorfos (febrero 7 de 2003) no presenta la aptitud de llevar información al juez, esto por cuanto su relación con los hechos no es directa, siendo que esta prueba contiene premisas generales sobre polimorfos pero no resulta aplicable al caso puesto que "[e] xisten numerosos ejemplos de litigios que han implicado controversias sobre la naturaleza, identidad, cantidad y unicidad de modificaciones cristalinas. Cada caso tiene su propio carácter e idiosincrasia y cada sustancia debe ser estudiada independientemente, asimismo, cabe esperar la existencia de avances en los métodos de predicción, aunque, posiblemente, éste es el aspecto más controvertido en este campo" (10, p. 66). 
El análisis específico de cada situación en torno a las formas polimórficas de un compuesto no es antecedente suficiente para aplicar lo planteado en otros casos, y ello no por su criterio jurídico, sino porque el análisis de la solicitud se realiza en particular para cada compuesto. Así las cosas, podemos hablar del polimorfismo como un fenómeno general que resulta específico para cada compuesto objeto de estudio.

Las demás pruebas fueron un testimonio y un peritazgo. En el proceso no se empleó el interrogatorio de parte, pese a que el CPC y el Código General del Proceso (CGP) admiten dicha prueba. La demandante, Novartis AG, solicitó tener en cuenta como prueba el testimonio del señor Bertrand Sutter, quien es doctor en ciencias pluridisciplinares y se encuentra estrechamente vinculado a la industria farmacéutica desde el año 1991, particularmente en el campo de investigación y desarrollo de nuevas entidades moleculares. Resulta interesante resaltar que el Dr. Sutter no sólo es un experto de interés para el litigio en cuestión, sino que se encuentra directamente relacionado con la invención reclamada en la solicitud colombiana 98-038983 al haber hecho parte del equipo de trabajo que entre los años 1994 y 2000 se vio involucrado en el desarrollo del medicamento Glivec ${ }^{\circledR}$ como co-inventor ${ }^{20}$.

Así las cosas, si bien no se pone en duda la idoneidad técnica del Dr. Sutter, cabría cuestionarse si resulta jurídicamente adecuado aceptar el testimonio de dicho experto como parte de este proceso, a pesar de ser coinventor del medicamento. No obstante lo anterior, el CE no desestimó la petición del laboratorio farmacéutico y procedió a aceptar dicho testimonio.

$\mathrm{Al}$ respecto, el CE consideró de interés particular las aseveraciones del Dr. Sutter mediante las cuales estableció lo siguiente como parte o con base en las respuestas del testimonio y en las preguntas previamente diseñadas por el demandante:

(i) No es posible predecir las propiedades de un sólido cristalino basándose únicamente en conocimientos en química; es decir, las propiedades tales como la solubilidad, higroscopicidad y flujo de un sólido cristalino no pueden ser asumidas a priori sin contar con investigación detallada ${ }^{21}$.

(ii) El cristal derivado de $\mathrm{N}$-fenil-2-pirimidinamina perseguido por la solicitud colombiana 98.038.983 se constituye como un polimorfo particular de sal de ácido metanosulfónico ${ }^{22}$.

(iii) Las enseñanzas del arte previo citado por la SIC -es decir, el documento EP 0564

20 Consejo de Estado, exp. 2003-00508, actora: Novartis AG, disponible en: http://190.24.134.67/documentos/boletines/100/S1/11001-03-24-000-2003-00508-01.pdf

21 Respuesta a la pregunta 9 del testimonio. Acta de recepción de testimonio y parcialmente transcrito en la sentencia.

22 Respuesta a la pregunta 11 del testimonio. 
409 (Imatinib) - no habrían permitido deducir de manera obvia la invención objeto de estudio (polimorfo $\beta$ del mesilato de Imatinib), toda vez que dicho arte previo solo hace referencia al "esqueleto" de N-fenil-2-pirimidinamina. En este sentido, el Dr. Sutter estableció que la anterioridad en cuestión contempla "más de 10000 estructuras químicas diferentes" ${ }^{23}$ que al ser combinados con cerca de 60 agentes para fabricar sales de uso farmacéutico generan una resultante superior a 600.000 posibilidades de las cuales se requeriría estudiar sus respetivas entidades polimórficas posibles. Lo anterior aplica igualmente para el caso del documento D2 (US 5,521,184) al tener en cuenta que el mismo corresponde a la patente americana del Imatinib.

De nuevo, las preguntas realizadas en el cuestionario al "testimoniante" tocan temas relacionados con las propiedades y ventajas del compuesto que se pretendía patentar, así como su relación con los documentos previos que sirvieron de fundamento para que la sic negara la patente al no cumplirse el requisito de altura inventiva. En resumen, el coinventor en sus respuestas busca reivindicar el esfuerzo y la novedad de la solicitud y refiere que la altura inventiva se cumple frente a la imposibilidad de deducir el procedimiento o camino a seguir de la lectura de los documentos encontrados en el arte previo.

Sin embargo, es menester recordar que nuestro sistema jurídico exige mínimos que fundamentan la legalidad y legitimidad del poder judicial. En este sentido, la inobservancia de los mismos puede desembocar en una violación de garantías constitucionales al debido proceso y de otros derechos de las partes.

La sana crítica es el sistema donde los principios antes citados pueden desarrollarse con libertad, dotando a las pruebas de plena validez y exigiendo del juez la observancia de la "sana razón, las formas procesales, el objeto de prueba, el tema probandum, y exigiéndole la motivación de sus providencias" (15, p. 249). La misma es definida según la Corte Constitucional así:

Las reglas de la sana crítica son, ante todo, las reglas del correcto entendimiento humano. En ellas interfieren las reglas de la lógica, con las reglas de la experiencia del juez. Unas y otras contribuyen de igual manera a que el magistrado pueda analizar la prueba (ya sea de testigos, peritos, de inspección judicial, de confesión en los casos en que no es lisa y llana) con arreglo a la sana razón y a un conocimiento experimental de las cosas (16).

Ahora bien, si el testimoniante emite un concepto para un tema determinado que tiene relación con su interés personal, como receptor de los efectos jurídicos del proceso en el cual está declarando, ello es motivo suficiente para que el juez valore ese aporte probatorio con detenimiento. Tal como comenta Amado (17, p. 17), la identidad del sujeto con relación al objeto "Apreciar el estado afectivo del testigo 
es, pues, uno de los mayores deberes del juez. [...] A veces al objeto se lo ve, no como es, sino como nos parece que es".

De la misma forma, no solo el régimen general de valoración de la prueba le indica al juez la cautela con la cual debe proceder frente a este tipo de situaciones, también el CPC hace referencia al mismo en sus artículos 216 numeral 2 y 218 que rezan respectivamente: "Son sospechosas para declarar las personas que en concepto del juez, se encuentren en circunstancias que afecten su credibilidad o imparcialidad, en razón de parentesco, dependencias, sentimientos o interés con relación a las partes o a sus apoderados, antecedentes personales u otras causas", y "Son inhábiles para testimoniar en un proceso determinado: [...] 2. Las demás personas que el juez considere inhábiles para testimoniar en un momento determinado, de acuerdo con las reglas de la sana crítica”. El artículo 211 CGP prevé algo similar, y también permite que cualquiera de las partes pueda tachar el testimonio de "personas que se encuentren en circunstancias que afecten su credibilidad o imparcialidad" 24 .

En referencia a las dos normas citadas con anterioridad, así como a los postulados que llenan de contenido la sana crítica, es dable deducir que al sistema jurídico colombiano le interesa que tanto la valoración probatoria como las pruebas en sí mismas guarden relación con el proceso, y, aún más importante, guarden una relación que se ajuste a los principios y el entramado normativo en sí mismo; ya por esto, a la luz de los principios citados y en razón del tamiz probatorio con el que cuenta el juez, la materia objeto de análisis de prueba le resultaría inconveniente para guardar la imparcialidad del proceso.

De esta manera, como resulta lógico - por su naturaleza de coinventor-, el testimonio que el Dr. Sutter presentó a lo largo de su declaración incluyó argumentos que defienden el nivel inventivo del polimorfo $\beta$, al asegurar que resulta improcedente considerar que las anterioridades citadas por la sic sugieren de manera alguna la manera de obtener el polimorfo en cuestión.

Ahora bien, por otra parte, el CE consideró la argumentación dada en modalidad de peritazgo por el experto en cristalografía José Antonio Henao Martínez, quien tiene título de doctor en química aplicada y es un reconocido experto en cristalografía que se desempeña actualmente como director de Laboratorio de Difracción de Rayos-X de la Universidad de Santander ${ }^{25}$.

La declaración del perito, considerada relevante para la sentencia, consta de las respuestas a doce preguntas que indagan acerca de la importancia del polimorfo $\beta$ y del arte previo relevante citado por la SIC; estas, en esencia, se resumen como sigue:

No es posible predecir con total certeza la existencia de polimorfos de un compuesto dado a partir del estado de la técnica de la química. La identificación certera de en-

24 Las partes pueden solicitar "tachar" los testigos, tanto bajo el artículo 218 CPC vigente durante el proceso judicial, como en la actualidad con base en el artículo 211 CGP.

25 Fuente: Universidad Industrial de Santander, página web: http://www.uis.edu.co/ webuis/es/investigacionExtension/acreditacionLaboratorios/laboratorioDifraccion/equipoTrabajo.html Consulta realizada el 14 de julio de 2015. 
tidades polimórficas es proporcional al tiempo de investigación invertido, y, por tanto, las condiciones requeridas para identificar nuevos polimorfos "de ninguna manera se pueden considerar obvias" [...]

No es posible predecir el comportamiento fisicoquímico, farmacéutico o biológico de un polimorfo. Una vez se identifica la presencia de polimorfos de un compuesto, se requiere de la investigación - a nivel de laboratorio- para establecer bajo qué condiciones se puede reproducir cada polimorfo, el comportamiento fisicoquímico, farmacéutico y biológico de los mismos y la determinación de su respectiva estructura cristalina [...]

El normalmente versado en la materia basado en las enseñanzas de las patentes EP 0564409 y US 5521184 no podría deducir de manera obvia el polimorfo $\beta$, puesto que "no es posible considerar obvio ni evidente el encontrar los parámetros adecuados para obtener un polimorfo".

Las enseñanzas de la referencia D3 (Farmacia de Remington) no afectan el nivel inventivo del polimorfo $\beta$ toda vez que "una persona medianamente versada en la técnica no podría deducir de manera obvia las condiciones para la preparación del polimorfo de N-feni1-2-pirimidinamina”.

A partir de la combinación del arte previo relevante citado por la sic "tampoco se podría deducir de manera obvia las condiciones para preparar el polimorfo de $\mathrm{N}$ fenil-2-pirimidinamina”.

Considerando que en los documentos EP 0564409 (D1), US 5521184 (D2) y en el libro Farmacia de Remington (D3) no existen antecedentes en el estado de la técnica que sugieran el método a seguir que conduzca de manera evidente al polimorfo [...], la solicitud de patente 98.038.983 sí posee nivel inventivo.

De esta manera, resulta claro a lo largo de la intervención del perito la provisión de argumentos que sostienen el reconocimiento de la labor investigativa asociada a la obtención de entidades polimórficas, y que, en últimas, se suman a favor de la patentabilidad de la invención en cuestión, al respaldar la actividad inventiva asociada al desarrollo de la misma, pero sin diferenciar claramente entre dos nociones clave: "esfuerzo investigativo" y "altura inventiva".

Así las cosas, los expertos citados - uno en calidad de testigo y otro de perito- brindaron argumentos generales asociados a las diferencias existentes entre los diversos polimorfos de un mismo compuesto químico y el "arduo trabajo investigativo" o trabajo experimental, requerido para la obtención de diferentes formas polimórficas, esto por cuanto, en su concepto, no existe obviedad en la obtención de dichas entidades toda vez que -según ellos- no es posible predecir la conformación o propiedades de las mismas sin la aplicación de investigación o experimentación de laboratorio. De igual modo, para el caso puntual de la forma 
cristalina $\beta$ perseguida por la solicitud, los especialistas consideraron que el estado del arte no cuenta con herramientas suficientes para predecir la existencia de formas cristalinas de Imatinib, y, por ende, tampoco para predecir la existencia y ventajas técnicas del polimorfo $\beta$ reivindicado.

Ahora bien, resulta pertinente recordar que el CE tuvo en cuenta otro aspecto que, aunque ajeno al caso puntual, resulta transversal al mismo. En este sentido, la parte demandante solicitó tener en cuenta para este proceso los argumentos dados por la sic en un litigio diferente, donde se discutían los aspectos asociados al patentamiento de polimorfos, y para evaluar la pertinencia de dichos argumentos se tomó nuevamente en consideración el concepto del mismo perito.

Transcribimos la pregunta nueve del cuestionario elevado ante el perito, en donde se parafrasean algunos apartes de la contestación de demanda presentada por la sIC (7 de febrero de 2003) en un proceso distinto ${ }^{26}$, para finalmente preguntar al perito si está de acuerdo con las mismas. Posteriormente se sintetizan los argumentos bajo los cuales se evidencian las posibles falencias que pudo tener la valoración probatoria del caso:

9. El apoderado de la sic dentro del memorial de contestación de demanda radicado con fecha 7 de febrero de 2003 dentro del trámite de la acción de nulidad y restablecimiento de derecho iniciado por Procaps y Ginopharm S.A..$^{27}$ en contra de las resoluciones que concedieron la patente y que se tramita bajo el expediente 8524 en el Consejo de Estado (documentos adjuntos) sostiene los siguientes argumentos:

A. Cuando se demuestra la presencia de polimorfos deben planearse trabajos experimentales para reproducir la obtención del cristal y determinar además si las propiedades difieren o no, en magnitud suficiente, como para alterar el comportamiento, fisicoquímico, farmacéutico o biológico. Valga resaltar que definitivamente al depender la obtención de polimorfos de factores tan diferentes y variables, no es posible considerar ni obvio ni evidente encontrar los parámetros adecuados dentro de esta diversidad de factores para obtener un polimorfo cristalino.

\section{$[\ldots]$}

C. La predicción de la estructura cristalina es aún una meta lejana y la preparación de fases específicas deseadas es también esquiva.

26 "Memorial de contestación de la demanda radicado con fecha 7 de febrero de 2003 dentro del trámite de acción de nulidad y restablecimiento del derecho iniciado por Procaps S.A. y Gynopharm S.A. en contra de las Resoluciones que concedieron la patente y que se tramita bajo el expediente 8254 en el Consejo de Estado".

27 En la sentencia de Imatinib se citan dos procesos, de un lado, el fallo proferido en el proceso 2003-00003, demandante: Pfizer, caso Ziprasidona; de otra parte se menciona el expediente 8254, demandante: Procaps-Gynopharm, sin sentencia en aquel entonces. 
D. [...] Cuando se demuestra la presencia de polimorfos deben plantearse trabajos experimentales para reproducir la obtención del cristal y determinar además si las propiedades difieren o no, en magnitud suficiente, como para alterar el comportamiento físico químico, farmacéutico o biológico [...].

9.1. A partir de su experticia en el tema, indique si está de acuerdo con cada una de las anteriores afirmaciones.

Perito: sí estoy de acuerdo.

De esta manera, frente a tales argumentos, el perito aseguró encontrarse de acuerdo al considerar que tales afirmaciones son "verdaderas y aplicables a los polimorfos en general".

Sin embargo, en nuestro criterio lo anterior no debería considerarse una regla general aplicable a todos los casos. Según el examen singular que adelante la SIC caso a caso sobre determinado polimorfo, el mismo puede cumplir o no con los requisitos de novedad y altura inventiva. "Los procedimientos para obtener polimorfos pueden ser patentables en algunos casos, si demuestran ser novedosos y cumplen con el requisito de altura inventiva" (18, p. 20) (resaltado fuera de texto).

Reiteramos a título enunciativo que, primero, se trajeron a colación enunciados dictados por la sic en un proceso distinto, lo que lesiona la singularidad o concreta valoración de los hechos; segundo, el perito (sin perjuicio de su destacada trayectoria académica) ha actuado en otros procesos del mismo talante con actores similares, lo cual eventualmente podría incidir en la imparcialidad del mismo; por ello existe la posibilidad de recusar a los peritos por las mismas circunstancias del juez. De la misma forma, no se pregunta qué tan rutinaria es la práctica de la obtención de polimorfos en el mundo farmacéutico. Por otro lado, observamos que los apartes refuerzan la idea de la dificultad o complejidad de la búsqueda del polimorfo, y sin embargo, como ya lo anotamos, el efecto técnico sorprendente no es evidente en el caso puesto que el compuesto cristalino no tiene un efecto terapéutico y, si bien es necesario llevar a cabo experimentación para obtener el cristal específico, esta sigue los métodos tradicionales y bien conocidos por la persona del oficio para obtener un polimorfo. Además, como se indicó anteriormente, el esfuerzo o complejidad técnica no es sinónimo de la altura inventiva, ni del efecto técnico sorprendente o inesperado.

A partir de lo anterior, sin perjuicio de las técnicas de laboratorio que sean empleadas, el experto promedio en cristalografía ostentaría un cuadro conceptual de la forma normalmente utilizada para llegar al resultado. La búsqueda de una forma estable para el desarrollo de un producto farmacéutico es una etapa necesaria y rutinaria dentro de la preformulación química, por la cual debe atravesar todo producto farmacéutico destinado a la administración a seres humanos. En este sentido cabe preguntarse si el esfuerzo reivindicado va determinado a encontrar una 
invención predecible o, por el contrario, una que haga un aporte sorprendente al estado actual de la técnica $(19)^{28}$.

En este punto vale la pena preguntarse si posiciones tales como la de India, en su sección 3 (d) de la Ley de Patentes, con la exclusión de patentabilidad de las sales, isómeros y polimorfos de cualquier compuesto que no presente beneficio terapéutico evidente (20), o la de Ecuador, en su recién aprobado "Código Ingenios"29 (21), resultan ser más adecuadas a la valoración del nivel inventivo que se requiere en el campo farmacéutico, pues la mera presunción de no obviedad por requerirse una etapa experimental resulta insuficiente, en especial en el caso de los polimorfos. Tal como se mencionó en el aparte técnico, el esfuerzo técnico, entendido como la necesidad de llevar a cabo una etapa experimental, no implica (necesariamente) que se obtenga un efecto técnico inesperado en el producto -para el caso de los polimorfos, un efecto terapéutico diferente al del compuesto de partida- no cristalino, por lo que la valoración del nivel inventivo debe ser analizada teniendo en cuenta este aspecto.

\section{B. Contestación DE LA DEMANDA}

Si bien no olvidamos que la sic en la presente controversia pudo haber referenciado las circunstancias que destacamos (esto es, la posibilidad teórica de recusación del perito y tacha del testigo), las mismas no fueron solicitadas por cuanto la accionada (la sIC) no contestó la demanda ${ }^{30}$. Sin embargo, es notable que nuestro sistema prevé estas posibilidades, y aunque la parte debe solicitarlas, el juez como máximo árbitro, con su conocimiento y sentido común, asigna el peso necesario a cada medio probatorio de acuerdo a la situación. No obstante lo anterior, la SIC sí presentó un escrito final de alegatos de conclusión que incluyó, entre otros, los siguientes argumentos:

Hay que tener en cuenta que la patentabilidad de una invención no depende de:

- El esfuerzo realizado por el inventor para obtener la invención.

- La inversión en tiempo o en dinero que el inventor haya realizado.

- La mayor o menor complejidad de la invención.

28 Consejo de Estado, Sala Primera, sentencia del 26 de junio de 2013, M.P.: Marco Antonio Velilla Moreno, actor: Schering Corporatión, exp. 200400226.

29 Proyecto del Código Orgánico de la Economía Social de los Conocimientos, Creatividad e Innovación, aprobado el 11 de octubre de 2016 por la Asamblea Nacional de Ecuador. El 9 de noviembre de 2016 el Presidente objetó 19 artículos de los 628 que tiene el proyecto; ver: http://www.asambleanacional.gob.ec/es/noticia/46933-ejecutivoobjeto-19-articulos-del-codigo-ingenios

30 Sin embargo, en respuesta al derecho de petición n. ${ }^{\circ} 15-163900$, radicado el 13 de julio de 2015 ante la sic por la Veeduría Ciudadana de Aspectos Científicos, Económicos y Legales del Acceso y Prestación de Servicios de Salud (vcacelapss), la SIC respondió que la demanda no fue contestada por cuanto nunca le fue notificada y en tal sentido nunca fue parte procesal en el expediente objeto de análisis. Sin embargo, constatando directamente con el expediente encontramos que se surtió la orden de notificar al Procurador delegado ante el Consejo de Estado y a la Superintendencia de Industria y Comercio (fls. 119-121). 
- El mérito reconocido o por reconocer de la invención.

- El valor económico que se le asigne al invento.

- Propiedades descubiertas después de haberse publicado la invención.

Postulados que, si bien no hacen referencia a los principales elementos que deben ser considerados durante la valoración probatoria, sí indican qué argumentos deben ser excluidos del análisis de patentabilidad, ya que los mismos resultan pertinentes al respecto e incluso reflejan circunstancias constatables. En el presente caso, al juez sí se le presentaron (si bien sólo al final del proceso) razones relevantes que confrontaban o cuestionaban los argumentos centrales de la demandante, pero estos no fueron tenidos en cuenta en forma detallada ${ }^{31}$ por el CE, aunque en la sentencia sí se transcriben otros apartados de los alegatos de conclusión, pero sin diferenciar entre esfuerzo investigativo y altura inventiva.

\section{FALLO}

Partiendo de los argumentos tomados en cuenta por el CE, este determinó en sesión del 9 de febrero de 2012, que era pertinente:

(i) Declarar nulidad de las Resoluciones n.o 04164 de febrero 25 de 2003 y 16268 de junio 16 de 2003, proferidas por el Superintendente de Industria y Comercio; y

(ii) Ordenar a la sic conceder la patente de invención a las reivindicaciones 1 a 13 de la solicitud de patente de invención "Modificación de cristal de un derivado de n-fenil-2-pirimidinamina, procesos para su fabricación y uso".

Posteriormente la sic concedió la patente mediante Resolución 24250 del 25 de abril de 2012.

\section{ESPECIALIZACIÓN DEL ÓRGANO DE REVISIÓN}

En otras jurisdicciones ciertos jueces en materia de patentes cuentan con formación en ciencias exactas - como ocurre en Estados Unidos con la Court of Appeals for the Federal Circuit (CAFC) ${ }^{32}$; de otra parte, su competencia no se basa en la localización geográfica o la legalidad de actos administrativos, sino en la especialidad temática, es decir, se dedican únicamente al análisis de patentes. Por ejemplo, el juez Alan D. Lourie tiene un doctorado en química ${ }^{33}$, el juez Raymond T. Chen es ingeniero eléctrico $^{34}$ y J.D. (Juris Doctor), título similar a un pregrado en derecho. Esto se

31 La sentencia del Consejo de Estado simplemente dice: "Las pruebas aportadas al proceso, como ya se advirtió, no fueron controvertidas ni desvirtuadas por la sic en las oportunidades pertinentes, amén de que no contestó la demanda”.

32 Sitio web: http://www.cafc.uscourts.gov/

33 http://www.cafc.uscourts.gov/judges/alan-d-lourie-circuit-judge

34 http://www.cafc.uscourts.gov/judges/raymond-t-chen 
explica por el contexto de ese país y por un volumen muy superior de casos en materia de patentes. En la EPO también existe una instancia de revisión en materia de patentes de composición interdisciplinaria denominada "Boards of Appeal", la cual define el número y calidad de personas encargadas de la solicitud según la dependencia de donde provenga: si su fuente es la división legal o de recibimiento, la solicitud será discutida por tres miembros legalmente cualificados; sin embargo, en caso de que la solicitud provenga de la sección de examen y verse sobre requerimiento de inaplicación de las disposiciones de la EPO o sobre la concesión de una patente, la misma será resuelta por dos miembros técnicos y uno jurídico, esto en caso de que la división de examen que revisó la solicitud estuviera conformada por menos de cuatro miembros; cuando la decisión haya sido concertada por cuatro miembros en la división de examen, o bien la naturaleza de la solicitud así lo requiera, el "Consejo de Apelación” deberá estar conformado por tres miembros técnicos y dos miembros jurídicos cualificados ${ }^{35}$.

Adicionalmente los examinadores que son contratados en la EPO deben dedicarse a un ítem específico dentro del área de conocimiento en la cual se van a desempeñar; así, quien cuenta con formación en química no tiene acceso a revisar todas las solicitudes que puedan ser allegadas en esta área del conocimiento, solo podrá revisar aquellas que se refieran a su especialidad, y por ello uno de los requisitos es "Diploma of completed university studies at Master's level in physics, chemistry, engineering or natural sciences" 36 .

En el contexto colombiano es interesante ver que, debido a la especialización a la que ha llegado la propiedad industrial, el examen de su juridicidad depende en vía gubernativa de una entidad especializada en el tema, esto es la sic, y sin embargo, una vez que se inician los recursos y demandas ante el CE, el contexto de debate cambia sustancialmente.

Resultado de una breve búsqueda de los perfiles de los actuales consejeros de Estado de la Sección Primera, esto es, los magistrados ${ }^{37}$ Guillermo Vargas Ayala, María Claudia Rojas Lasso, María Elizabeth García Gonzales y Roberto Augusto Serrato Valdés, encontramos que ninguno de ellos cuenta con especialización o maestría en propiedad intelectual, y de la misma manera, ninguno de ellos tiene formación en áreas técnicas tales como química, farmacia, biología o ingeniería, aunque tienen trayectorias jurídicas destacadas.

Así pues, la propiedad intelectual tiene trascendencia no solo para el interés privado sino para el público, y en razón de ello la seguridad jurídica aboga por que el perfil de la persona que desempeñe el papel de juzgador cumpla los requisitos previstos para ubicarse en determinada jurisdicción.

En Colombia la concesión o negación de una patente se materializa en actos administrativos, por esto la acción de nulidad y restablecimiento del derecho de 
una decisión de la sic buscar cuestionar la validez de dicho acto administrativo. Por ello el ente competente es el Consejo de Estado.

Sin embargo, resulta desfasado que el ente administrativo encargado de revisar todas las controversias con el Estado sea quien resuelva una controversia que versa sobre un tema tan específico. Detengámonos sobre la competencia de la Sección Primera del CE, sección integrada por cuatro magistrados (art. 110 Ley 1437 de 2011).

Sus funciones están establecidas en el Reglamento del CE y son, entre otras:

- Procesos de simple nulidad y de nulidad y restablecimiento que no sean asignados a otras secciones.

- Recurso extraordinario de revisión sobre sentencias de única instancia de tribunales.

- Recurso extraordinario de revisión sobre sentencias de tribunales sobre pérdida de investidura.

- Controversias en materia ambiental.

- Las demás de carácter administrativo para las cuales no exista regla especial de competencia.

A este punto parece ser la especialización un punto importante a tener en cuenta dentro de las futuras modificaciones que deban realizarse al régimen de propiedad intelectual, ya que la Decisión 486 de la CAN trae al panorama la calidad o el perfil de la persona que examina, no de la que juzga, quien, deduciríamos, es la persona especializada en su rama; si a lo anterior le sumamos la situación de congestión judicial que atraviesa el país desde hace años y el hecho de que el cE ha aumentado el porcentaje de recepción de casos por revisar en un 16\% desde el año 2000 (22 pág. 48), cifra que tiende a crecer con las competencias asignadas a este tribunal y los retos que se avecinan en razón de la justicia transicional, la cual necesariamente usará como instrumento las vías contenciosas, temas de esta trascendencia pueden no tener la atención que requieren.

Aunque no es objeto de este artículo hacer un análisis comparado de las instancias administrativas y judiciales en materia de patentes, es oportuno traer a colación los ejemplos citados para observar el panorama a escala global. Se advierte que en Colombia el nivel de especialización del órgano encargado de reconsiderar o no la concesión de una patente se encuentra rezagado frente a los órganos de otros países encargados de revisar las decisiones emitidas en vía gubernativa o en primera instancia.

Los órganos e instituciones, ante diversas circunstancias tales como el aumento de uso del sistema, el aumento del nivel de especialización, las nuevas tecnologías disruptivas en ámbitos como la biotecnología (23), el cambio de paradigmas, la re-categorización de la importancia de determinados temas, se ven en la necesidad de adecuarse a reformas administrativas que pueden ser necesarias y pertinentes.

La valoración de las pruebas depende del criterio de quien las observa; así las cosas, la dilucidación de temas que pertenecen a otras áreas del conocimiento 
requiere del concepto técnico de un tercero, quien al expresar su idea lo hace en el lenguaje de su área, el cual muchas veces puede escapar al completo entendimiento del receptor; y si el receptor no cuenta con el conocimiento suficiente para entender el dictamen, la capacidad de confrontación y análisis se verá socavada, elevando el concepto rendido a "verdad técnica". En esta sentencia el asunto se agrava por la no contestación de la demanda por la sic, como se detalla en el siguiente apartado.

\section{Caso Imatinib en otras jurisdicciones}

En este panorama se destaca la polémica suscitada por el litigio de interés mundial llevado a cabo en India, en donde el titular Novartis AG buscó protección para el polimorfo $\beta$ de Imatinib pero - tras cerca de una década de litigios- la Corte Suprema se negó rotundamente a otorgar la patente, debido a que el Imatinib es una molécula ya conocida en el arte previo, y por tanto la nueva solicitud relacionada con la forma polimórfica carecía de información técnica que respaldara una mejora en la eficacia terapéutica asociada al polimorfo; en otras palabras, la Corte consideró que la solicitud de patente asociada al polimorfo $\beta$ carecía de novedad y nivel inventivo al no contar con ninguna ventaja adicional a las ya conocidas para el Imatinib y sus sales (5) (20).

Dicho panorama se encuentra plenamente justificado en la fortaleza de la normatividad en temas de propiedad intelectual que caracteriza a la legislación india, en donde el análisis de cumplimiento de los requisitos de novedad y nivel inventivo resulta considerablemente más estricto en comparación con otras legislaciones $-\mathrm{p}$. ej., la de Estados Unidos y Europa-, particularmente en temas críticos tales como los relacionados con solicitudes de patente para polimorfos, sales, isómeros y otro tipo de compuestos derivados de moléculas farmacéuticamente aceptables. En este sentido, la legislación india estableció de manera clara en la norma The Patents (amendment) Act 2005 n. ${ }^{\circ} 15$ de $2005^{[38]}$ :

No se considerará una invención [...] (d) el mero descubrimiento de una nueva forma de una sustancia conocida la cual no resulte en el mejoramiento de la eficacia ya conocida de la sustancia o el mero descubrimiento de cualquier nueva propiedad o nuevo uso para una sustancia conocida [...] Para el propósito de esta cláusula, sales, esteres, éteres, polimorfos, metabolitos, formas puras, tamaño de partícula, isómeros, complejos, combinaciones y otros derivados de sustancias conocidas deberán ser consideradas la misma sustancia, a menos que los mismos difieran significativamente en propiedades relacionadas con su eficacia ${ }^{39}$ (trad. libre).

38 Disponible en wipo LEx: http://www.wipo.int/edocs/lexdocs/laws/en/in/in065en.pdf 39 " $3(d)$ the mere discovery of a new form of a known substance which does not result in the enhancement of the known efficacy of that substance or the mere discovery of any new property or new use for a known substance or of the mere use of a known process, machine or apparatus unless such known process results in a new product or employs at least one new reactant. Explanation.-For the purposes of this clause, salts, esters, ethers, polymorphs, 
Así pues, en dicha legislación se limitaba la protección mediante DPI para los polimorfos, lo cual se vio plenamente reflejado en el caso Imatinib, toda vez que las solicitudes de ese tipo son consideradas carentes de nivel inventivo, sumado al hecho de que en ausencia de superioridad terapéutica no existe ninguna justificación para otorgar protección. En este mismo sentido pueden resaltarse los casos de otras legislaciones que limitan la patentabilidad de este tipo de derivados de interés farmacéutico, tales como las de Filipinas (Universally Accessible Cheaper and Quality Medicines Act 2008, Republic Act n. ${ }^{\circ}$ 9502) $)^{40}$, Argentina (Res. conjunta del Ministerio de Industria, Ministerio de Salud e Instituto Nacional de la

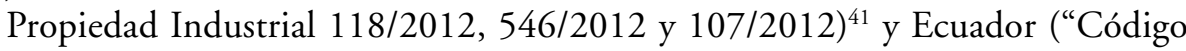
Ingenios”, presentado en junio de 2015 a la Asamblea -Congreso- de Ecuador y aprobado en octubre de 2016). También son relevantes las Directrices para el examen de solicitudes de patentes relativas a productos farmacéuticos expedidas en 2016 por el PNUD (24), que, así como la OMPI, es organismo técnico del sistema de Naciones Unidas.

Dichas normas y directrices tienen elementos en común con las Guías para el examen de patentes farmacéuticas de ICTSD, WHO y UNCTAD $(18$, p. 12) que señalan:

El polimorfismo es una propiedad inherente a la materia en su estado sólido. Los polimorfos no se crean, sino que se descubren. Las oficinas de patentes deben tomar conciencia de la posible ampliación injustificada del período de protección, que surge del patentamiento sucesivo del principio activo y sus polimorfos, incluyendo hidratos/ solvatos. Los procedimientos para obtener polimorfos pueden ser patentables en algunos casos, si demuestran ser novedosos y cumplen con el requisito de altura inventiva.

De otra parte es posible que, antes de expedir esas normas más estrictas en materia de polimorfos, los países enunciados hayan hecho un análisis de costo-beneficio respecto del hecho de tener estándares más laxos o flexibles frente al tema, como parece sugerirlo un sector de la doctrina jurídica $(25)^{42}$.

metabolites, pure form, particle size, isomers, mixtures of isomers, complexes, combinations and other derivatives of known substance shall be considered to be the same substance, unless they differ significantly in properties with regard to efficacy".

40 Disponible en: http://www.wipo.int/wipolex/en/details.jsp?id=5204

41 Disponible en: http://www.wipo.int/edocs/lexdocs/laws/es/ar/ar109es.pdf

42 "Si bien la aplicación de bajos estándares de patentabilidad puede permitir a las empresas locales obtener patentes, los eventuales beneficios para la industria local mediante esa politica parecen ser superados por los costos vinculados con la proliferación de patentes sobre cambios técnicos menores. Dadas las asimetrías en las capacidades de innovación entre las industrias locales y las extranjeras, los bajos estándares de patentabilidad, en última instancia, beneficiarán a las últimas. Más importante aún, la exclusión de la competencia genérica legítima tiende a afectar a la salud pública de manera negativa, por el menor acceso a los medicamentos" (Bergel et al., 2013). 


\section{CONCLUSIONES}

A partir de la información expuesta, resulta evidente la falta de consenso existente entre las interpretaciones de la SIC y del CE, en términos de evaluación de la existencia de nivel inventivo asociado a la generación de formas polimórficas, cuando menos en el caso específico. En este sentido, si bien la sic es la entidad habilitada para la valoración técnica de las solicitudes de patente, la decisión de la misma fue desestimada por el CE, que, basado en conceptos técnicos jurídicamente discutibles, ordenó otorgar patente a la solicitud del polimorfo $\beta$ de Imatinib.

Así pues, el análisis de nivel inventivo llevado a cabo por la sic se basó en una postura "tradicionalista", en donde no se contemplan consideraciones particulares para grupos de invenciones tales como los polimorfos, mientras que la postura del CE consideró que la existencia de un esfuerzo técnico, enmarcado en la experimentación realizada, y ventajas técnicas asociadas a la forma polimórfica, eran suficientes para atribuir nivel inventivo a la solicitud, aun en ausencia de un efecto superior farmacológico asociado.

Lo anterior se enmarca en la discusión actual en torno a la pertinencia de otorgar protección a las denominadas patentes secundarias, al abrir la puerta a su aceptación en una instancia ajena a la competente en vía administrativa.

Así mismo, al revisar las reivindicaciones que concedió la sıc, en razón a la resolución de revocatoria de la negación y restablecimiento del derecho del solicitante de la patente, ordenada por el CE, se observa que concedió materia relacionada con usos, pese a ser materia no patentable en Colombia. Esto deja ver que debe existir un adecuado estudio de las reivindicaciones por parte del CE cuando resuelve revocar una negación de patente, y que la sic en esta instancia debe tener oportunidad de revocar sus actos administrativos siempre y cuando se cumpla con los requisitos de la Decisión 486, especialmente en lo referido a la materia no considerada invención, excepciones a la patentabilidad, usos y segundos usos.

Pese a la visibilidad mediática que ha tenido el caso Imatinib, no es un caso representativo del estado actual de la patentabilidad de polimorfos en Colombia. Entre 2003 y 2015 la posición de la sic sobre este tipo de solicitudes de patente cambió, y actualmente hay criterios más explícitos y cierta "apertura" a partir del Instructivo de examen de 2012, al reconocerle la novedad a la molécula cristalina y dar los lineamientos para poder reivindicar los polimorfos (26, p. 186) (27). De otra parte, sería inadecuado hacer generalizaciones sobre la posición del CE, pero hay al menos tres casos en donde este CE ha ordenado revocar la decisión de negación de la sic y conceder patentes a polimorfos; tales casos son: Atorvastatina, Ziprasidona y Arzoxifeno ${ }^{43}$; en otro confirmó la negación: se trata del caso

43 Hay varias sentencias de polimorfos proferidas por el Consejo de Estado, en diverso sentido. Pese a las especificidades técnico-jurídicas de cada una, de modo no exhaustivo pueden mencionarse casos donde el CE ha ordenado revocar la negación y conceder la 
Triazolona, sobre "vacunas con base en composiciones adyuvantes de saponinas y oligonucleótidos inmunoestimulantes ${ }^{44}$; y en otro(s) "confirmó" la concesión (es decir, no se accedió a declarar la nulidad de la concesión) respecto del proceso para convertir atorvastatina cristalina en atorvastatina amorfa ${ }^{45}$; además, existen pronunciamientos sobre otro tipo de patentes secundarias: $\operatorname{sales}^{46}$, etc.

Sin caer en generalizaciones, ciertos elementos conceptuales expuestos sobre diferencias entre esfuerzo investigativo y altura inventiva, valoración probatoria de testimonios y peritazgos analizados en este caso, pueden ser útiles en otras situaciones.

El aumento en el número de solicitudes de patente en Colombia, así como el aumento en la tasa de concesión y la complejidad técnica del tema, abre la discusión sobre cuáles deben ser los mecanismos de control y las instancias más idóneas en vía administrativa y en vía judicial para salvaguardar el cumplimiento de los requisitos de patentabilidad, la calidad y el rigor durante el examen, la concesión y negación de patentes, y su revisión judicial, de manera que no se afecten indebidamente la libre competencia y derechos fundamentales de los ciudadanos, tales como la salud, a la vez que se proteja la propiedad intelectual adecuadamente, cuando corresponda.

\section{Bibliografía}

1. Capdeville, Renaud et al. "Glivec (sti571, Imatinib), a rationally developed, targeted anticancer drug", Nature Reviews Drug Discovery, 2002, vol. 1 (7), págs. 493-502.

2. IQBAL, NIDA, IQBAL NAVEeD. "Imatinib: A Breakthrough of Targeted Therapy in Cancer", Chemotherapy Research and Practice, 2014, vol. 2014, págs. 9.

3. FDA. U.s. Food and Drug Administration. [En línea] 2009. http://www.fda.gov/ Drugs/DrugSafety/PostmarketDrugSafetyInformationforPatientsandProviders/ ucm110502.htm

4. EMA. European Medicines Agency. [En línea] 2013. http://www.ema.europa.eu/ docs/es_ES/document_library/EPAR_-_Product_Information/human/000406/ WC500022207.pdf

5. Gabble, Ravinder y Kohler, Jillian Clare. "To patent or not to patent? the case of Novartis' cancer drug Glivec in India", Gabble and Kobler Globalization and Health, 2014, vol. 10, p. 3.

6. Panel de Alto Nivel del Secretario General de las Naciones Unidas sobre el Acceso a los Medicamentos. Report of the United Nations Secretary-General's High-Level Panel on Access to Medicines: Promoting innovation and access to

patente: Atorvastatina (2009), ref. 2003-00256, Ziprasidona (2011), ref. 2003-00003, Arzoxifeno (2013), ref. 2007-00054.

44 En otros casos se negaron las pretensiones de la demanda y no se revocó la negación de la patente; p. ej., Triazolona (2013), ref. 2004-00226.

45 Exp. 11001-03-24-000-2002-00273-01 (2012).

46 Ref. 2003-00450 (2015), sales de Ziprasidona con Ciclodextrina 2002-00231 (2012). 
health technologies. Nueva York: s.n., 2016, p. 70. Obtenido de: http://www. unsgaccessmeds.org/final-report/

7. Superintendencia de Industria y Comercio. Estadisticas 2015. Nuevas Creaciones. 2015/12/31.

8. Qiu, Yıнong, y otros, [ed.]. Developing Solid Oral Dosage Forms: Pharmaceutical Theory \& Practice, s.l: Academic Press, 2009, pp. 25-37.

9. Brittain, Harry G., [ed.]. Polymorphism in Pharmaceutical Solids. Segunda, s.l. : Drugs and the Pharmaceutical Sciences, 2009.

10. Prohens, R. y Puiguaner, C. "Polimorfismo en la Industria Farmacéutica. El farmacéutico Unitat de Química Fina”, Serveis Cientificotècnics, Universitat de Barcelona, 2007, 373, pp. 58-68. Obtenido de: http://www.pcb.ub.edu/ plataformes-mixtes/web/docs/4-IndustriaFarmaceutica.pdf

11. Ahn, Hyewon. Second Generation Patents in Pharmaceutical Innovation, s.l: Munich Intellectual Property Law Center - MIPLC, 2013, vol. 19, pp. 312-320.

12. Lizarazo-Cortés, Óscar y Lamprea, Natalia. "Implementación del procedimiento acelerado de patentes ( $\mathrm{PPH}$ ) en Colombia. Análisis jurídico, técnico y efectos iniciales", Revista La Propiedad Inmaterial, 2014, vol. 18, pp. 281-321.

13. Lizarazu, Rodolfo. Manual de propiedad industrial, Bogotá: Legis, 2014.

14. Cañón, Pedro Alejo. Práctica de la prueba judicial, Bogotá: ecoe, 2009.

15. Cuello Iriarte, Gustavo. La sana crítica, sistema de valoración de la prueba judicial, Bogotá: Pontificia Universidad Javeriana, 2007.

16. Corte Constitucional de Colombia, Sentencia C-202/05, M.P.: J. Araújo.

17. Amado, Adip. "El testimonio y la confesión", en Gómez, J. (comp.), El testimonio y la confesión, Compilacion y extractos, Bogotá: Bolivariana, 1995.

18. ICTSD, who, UnCtad-Correa, Carlos. Guidelines for the examination of pharmaceutical patents: developing a public health perspective - A Working Paper, Ginebra: ICTSD, WHO, UNCTAD, 2006, p. 66.

19. CE, 2004 00226, M. Velilla. 2004 00226, s.l.: CE, 26 de junio de 2013.

20. Conde, Carlos y Consuegra, Saray. "Un problema de acceso a medicamentos: El caso Imatinib (Glivec) en Colombia”, Boletín virtual del Departamento de Propiedad Intelectual, Universidad Externado de Colombia. [En línea] Julio de 2015. http://propintel.uexternado.edu.co/un-pr

21. Lizarazo-Cortés, Óscar. "Código Ingenios y su acertada apuesta para elevar la calidad de las patentes", El Telégrafo, 9 de julio de 2016, obtenido de: http://www.eltelegrafo.com.ec/noticias/punto-de-vista/1/codigo-ingenios-ysu-acertada-apuesta-para-elevar-la-calidad-de-las-patentes

22. Coronado B, Ximena. La congestión judicial en Colombia, tesis, Bogotá : Universidad Javeriana, 2009, obtenido de: http://www.javeriana.edu.co/biblos/ tesis/comunicacion/tesis202.pdf

23. Lamprea, Natalia y Lizarazo-Cortés, Óscar. "Técnica de edición de genes CRISPR / cas9. Retos jurídicos para su regulación y uso en Colombia”, Revista La Propiedad Inmaterial, vol. 21, 2016, pp. 79-110. 
24. Undp, United Nations Development Programme. Guidelines for the Examination of Patent Applications relating to Pharmaceuticals, 2016, p. 48, obtenido de: http://www.undp.org/content/undp/en/home/librarypage/hiv-aids/guidelinesfor-the-examination-of-patent-applications-relating-t.html

25. Bergel, Salvador Darío y Correa, Carlos. Régimen Legal de la Patentes de Invención, s.l.: La Ley - Thomson Reuters, 2013.

26. Phrma. Pharmaceutical Research and Manufacturers of America (PhrmA) Special 301 Submission 2014, 2014.

27. Correa, Óscar. "Nuevo entorno de la práctica de patentes en Colombia", La República, 4 de diciembre de 2013, obtenido de: http://www.larepublica. $\mathrm{co} /$ consultorios/nuevo-entorno-de-la-pr\%C3\%A1ctica-de-patentes-encolombia_88526

28. Roubier, Paul. Le droit de la propriété industrielle, t. II, Paris: Syrey, 1952. 